HEAD AND NECK

\title{
Nerve and vein preserving neck dissections for oral cancers: a prospective evaluation of spinal accessory nerve function and internal jugular vein patency following treatment
}

\author{
Preservazione del nervo accessorio spinale e della vena giugulare interna \\ durante dissezione del collo per carcinoma del cavo orale: valutazione prospettica \\ della funzione del nervo e della pervietà della vena dopo trattamento
}

\author{
G.R. KUMAR REDDY ${ }^{1}$, N. HULIKAL ${ }^{1}$, A.Y. LAKSHMI², B. VENGAMMA ${ }^{3}$ \\ ${ }^{1}$ Department of Surgical Oncology, ${ }^{2}$ Department of Radiology, ${ }^{3}$ Department of Neurology, Sri Venkateswara \\ Institute of Medical Sciences, Tirupati, Andhra Pradesh, India
}

\section{SUMMARY}

Nerve and vein preserving modification of the radical neck dissection is commonly used in the management of oral squamous cell cancers. There is limited literature addressing nerve function and vein patency following treatment. We prospectively analysed 65 patients with nerve conduction study using surface electromyography at baseline, 1 month and 6 months post-surgery and colour Doppler of the internal jugular vein at baseline and 1 month post-surgery. We also studied functional outcomes of nerve sparing with arm abduction test and Neck Dissection Quality of Life questionnaire. There was a statistically significant increase in mean latency of motor action potential and decrease in the mean amplitude of the motor action potential following surgery, suggesting nerve dysfunction. Following surgery, there was a significant decrease in the diameter of the vein as well as an increase in the velocity of blood flow; there was partial thrombus in 5\% of individuals. In conclusion, even though nerve dysfunction compromised shoulder abduction, vein dysfunction rarely resulted in any significant clinical impact.

KEY WORDS: Neck dissection • Mouth neoplasms • Accessory nerve • Jugular veins • Quality of life

\section{RIASSUNTO}

La preservazione del nervo accessorio spinale e della vena giugulare interna durante la dissezione del collo è una pratica comune nella gestione del carcinoma squamoso del cavo orale. Tuttavia, la letteratura riguardante la funzione del nervo e la pervietà della vena è limitata. Pertanto, abbiamo analizzato retrospettivamente 65 pazienti e abbiamo studiato tramite elettromiografia superficiale la funzione del nervo spinale basale e dopo 1 mese e dopo 6 mesi dall'intervento e tramite color doppler la pervietà della vena giugulare interna basale e dopo 1 mese dall'intervento. Abbiamo inoltre studiato i risultati funzionali mediante il test di abduzione del braccio e il questionario "Neck dissection Quality Of Life". È risultato un aumento statisticamente significativo della latenza media del potenziale d'azione motorio e un decremento dell'ampiezza media del potenziale d'azione motorio in seguito a trattamento chirurgico, suggerendo quindi una disfunzione del nervo. Inoltre, in seguito all'intervento, c'è stato un decremento altrettanto significativo del diametro della ven, e, parallelamente, un incremento della velocità del flusso sanguigno e nel $5 \%$ dei pazienti è stata documentata una trombosi parziale. In conclusione, da una parte la disfunzione nervosa ha compromesso il movimento di abduzione del braccio, dall'altra la disfunzione venosa raramente ha avuto un impatto clinico.

PAROLE CHIAVE: Dissezione del collo $\bullet$ Carcinoma del cavo orale $\bullet$ Nervo accessorio $\bullet$ Vena giugulare $\bullet$ Qualità della vita

Acta Otorhinolaryngol Ital 2018;38:7-12

\section{Introduction}

Squamous cell carcinomas of the head and neck (HNSCC) account for $90 \%$ of all malignant diseases of the head and neck region ${ }^{1}$. The oral cavity lined by stratified squamous epithelium is the most common site of HNSCC. The highest incidence of carcinomas of oral cavity and oropharynx are in South East Asia, where chewing tobacco with betel quid (paan) is a common practise. According to GLOBOCAN 2012, the estimated 5 year prevalence of lip and oral 
cavity malignancies worldwide is $2.2 \%$ with a male preponderance $(3.1 \% \text { vs. } 1.4 \%)^{2}$.

The single most important factor affecting prognosis in HNSCC is the status of cervical lymph nodes at presentation, and more than $40 \%$ of patients with oral and pharyngeal squamous cell carcinomas present with regional spread $^{3}$. The management of the neck in oral cancers depends on whether the nodes are clinically involved, and if not then on the risk of occult metastasis. For oral cancers, the estimated incidence of subclinical disease in a clinically N0 neck is 15 to $20 \%$. When regional metastasis is clinically detected, comprehensive clearance of all regional lymph nodes is recommended, whereas for a cNO neck, selective neck dissection is performed. The understanding that optimal lymph nodal clearance can be achieved with conservative surgical procedures such as preservation of the spinal accessory nerve (SAN) and internal jugular vein (IJV) without the added risk of recurrences has shifted the focus to so-called modified radical neck dissections ${ }^{4}$. Among the various modifications, modified neck dissection (MND) type-II preserving SAN and IJV is popular, with the preservation being thought to reduce the morbidity of neck dissection ${ }^{5}$. Though MND type II preserves two of the most important non-lymphatic structures, few studies have shown that the function of the preserved nerve as well as the patency of the vein may be suboptimal ${ }^{67}$. There is paucity of published data on the functionality and quality of life after these non-radical surgeries at present, and hence the present study was undertaken to look at the overall impact of MND type II surgery with specific reference to function of the SAN and patency of the IJV together with the postoperative quality of life.

\section{Materials and methods}

This was prospective study of consenting patients with biopsy proven oral squamous cell cancer (OSCC) of operable cT (T1 to T4a, AJCC/TNM 2010) stage undergoing primary surgery with modified neck dissection type II (defined as preservation of both the SAN and IJV) over a period of one year from June 2014 to May 2015. The main exclusion criteria included cN2 or N3 disease, prior treatment (surgery, radiotherapy or chemotherapy), gross invasion of XI nerve or internal jugular vein either preoperatively or at surgery, previous or intra-operative injury to the nerve or vein, cardiac pacemaker (contraindication for nerve conduction studies), patients on anticoagulant therapy and patients who developed postoperative complications that prevented evaluation at 3 to 4 weeks.

All eligible patients were subjected to nerve conduction study (NCS) for measurement of amplitude and latency of Motor Action Potential (MAP) of the Spinal Accessory Nerve and colour Doppler study for calibre, patency and velocity of the IJV preoperatively. Patients underwent appropriate surgery including nerve and vein sparing neck dissection (MND type II). Following surgery, a repeat NCS was done at one and 6 months postoperatively and colour Doppler evaluation of the vein was done at one month postoperatively. The angle of arm abduction was measured with a goniometer pre-and post-operatively, and the quality of life after neck dissection was assessed by a Neck Dissection Quality of Life (NDQOL) questionnaire as described previously by Giordano et al. ${ }^{8}$ (Table I) and the results were compared using a chi square test. Postoperatively, the use of adjuvant chemoradiation or radiotherapy was based on standard guidelines.

\section{Nerve conduction study}

The nerve conduction study was done by MEDELEC synergy 10 channel machine using surface electrodes to obtain electrophysiological readings from the nerve and muscles. The test was carried out in a sitting position as per the recommendations of Surface Electro MyoGraphy for the Non-Invasive Assessment of Muscles (SENIAM) project group ${ }^{9}$. The nerve was stimulated at one end and recorded at other end near the muscle for $0.2 \mathrm{msec}$ with three times the supramaximal stimulus. The amplitude and latency of the MAP were measured and compared.

\section{Colour Doppler of the IJV}

In the supine position, after applying coupling gel over the neck, the ultrasound probe was placed over the IJV

Table I. Arm abduction test and NDQOL questionnaire ${ }^{8}$

\begin{tabular}{lc} 
Angle of arm abduction & Score \\
Up to less than $90^{\circ}$ & 1 \\
Up to more than $90^{\circ}$ but less than $150^{\circ}$ & 2 \\
Up to more than $150^{\circ}$ but less than $180^{\circ}$ & 3 \\
Up to $180^{\circ}$ but with pain or effort & 4 \\
Up to $180^{\circ}$ but without pain or effort & 5 \\
NDQOL questionnaire & Score \\
Are you bothered by shoulder or neck stiffness? & $1-5$ \\
Are you bothered by shoulder or neck pain? & $1-5$ \\
Are you bothered by numbness of your neck? & $1-5$ \\
Are you bothered by constriction of your neck? & $1-5$ \\
Do you think the shoulder dropped? & $1-5$ \\
Do you have difficulty in reaching objects above your neck? & $1-5$ \\
Are you bothered by appearance of your neck? & $1-5$ \\
Total & $7-35$ \\
\hline
\end{tabular}


to look for signs of thrombus (internal echoes and non-compressibility). The differential flow of blood in veins was detected by sound waves by measuring the calibre, velocity and phasic variation.

\section{Statistical analysis}

All data were recorded in a predesigned Performa and were managed using Microsoft Excel 2007; data were presented as mean $\pm \mathrm{SD}$. The paired $t$ test and repeated measure ANOVA were used for qualitative data and the chi square test was used for quantitative data. Statistical analysis was performed using SPSS (statistical package for social sciences) Version 21 software, and a $\mathrm{p}$ value less than 0.05 was considered significant.

\section{Results}

Over a period of one year, of the 100 consenting patients with biopsy proven OSCC, $35 \mathrm{did}$ not meet the selection criteria for various reasons (Fig. 1). All 65 eligible patients, following preoperative baseline NCS and colour Doppler of the IJV, underwent neck dissection with preservation of the SAN and IJV. Five patients with intra-operative injury to the nerve and 12 patients with post-operative wound complications were also excluded from the final analysis. Of the remaining 48 patients, 6 patients were lost to follow-up and two patients died of malignancy (Fig. 1). The mean ( \pm SD) age of patients was $55.86( \pm 10.22)$ years, the majority were female (50 of 65, 77\%) and most had left side lesions (45, $69 \%$ ). A total of 42 of the 65 patients were less than 60 years of age and 37 patients received postoperative adjuvant neck irradiation.

\section{Nerve conduction study}

Latency: The mean $( \pm \mathrm{SD})$ preoperative, at 1 months and at 6 months latency of the MAP of the spinal accessory nerve were $2.13( \pm 0.79), 2.75 \pm 1.16$ and 3.01 $( \pm 1.51)$ msec respectively. The differences were sta-

Fig. 1. Consort diagram.

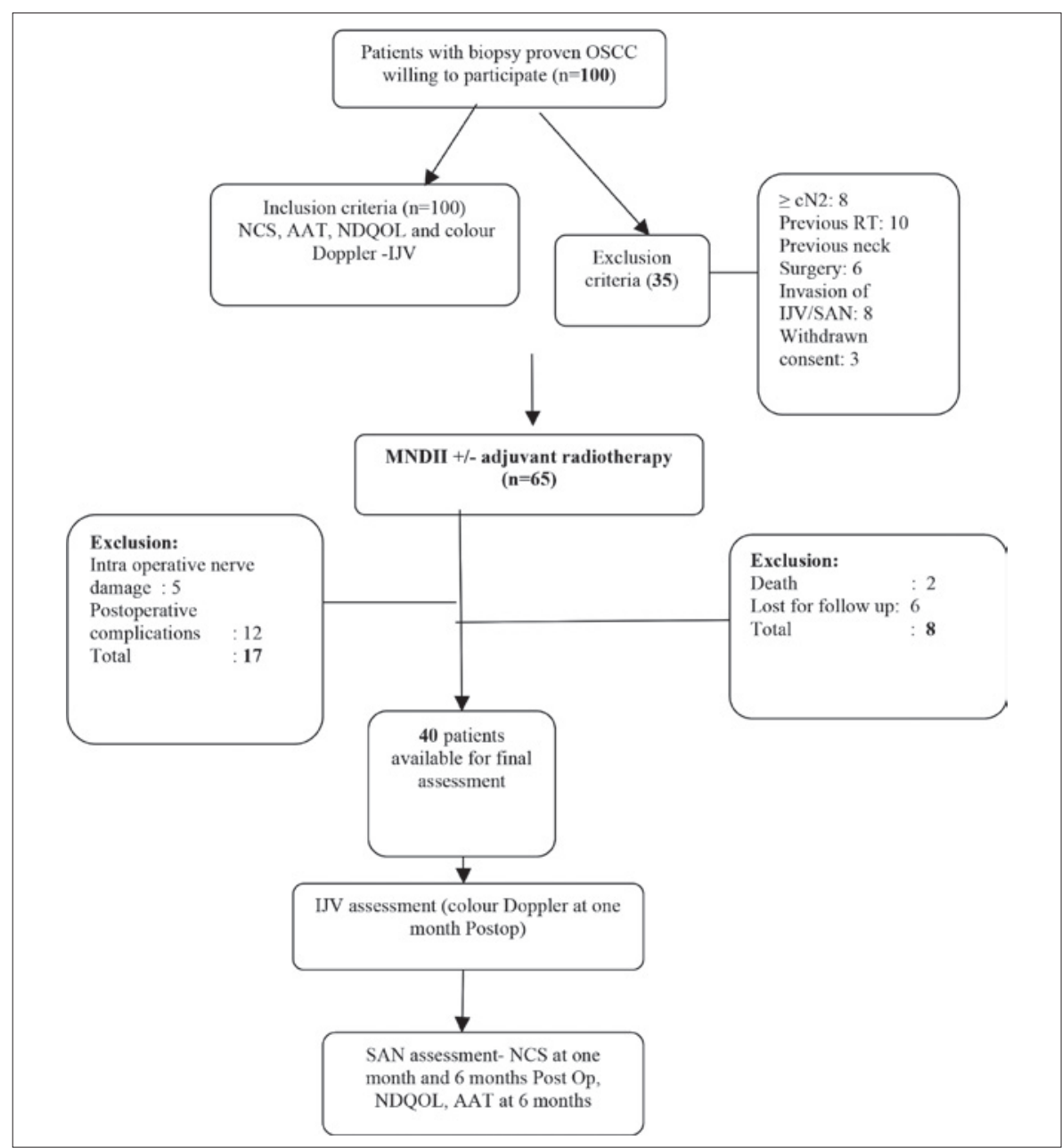

OSCC: oral squamous cell carcinoma; NCS: nerve conduction study; AAT: arm abduction test; NDQOL: neck dissection quality of life questionnaire; IJV: Internal jugular vein; RT: radiotherapy.

tistically significant $(\mathrm{p}<0.001)$. The latency (Figs. 2, 3) showed an increasing trend at one month and at 6 months postoperatively in most subjects except in 6 , who showed an increase in latency at one month and decrease in latency at 6 months, but the value never fell below the pre-operative value. Interestingly, 5 of these 6 patients did not receive any postoperative neck irradiation.

Amplitude: The mean ( \pm SD) amplitude of MAP expressed in $\mathrm{mV}$ at baseline, 1 month and 6 moths postoperative were $8.06( \pm 0.35), 5.02( \pm 0.51)$ and 4.67 $( \pm 0.48)$ respectively. The amplitude of individual subjects (Figs. 4, 5) decreased at one month and 6 months progressively (ANNOVA, $\mathrm{p}<0.001$ ) except in 6 patients, who showed an increase in amplitude at 6 months, but this never reached the pre-operative value. Again, 5 of these did not receive any neck irradiation. Though there was a decrease in mean amplitude at one month $(2.2 \pm 0.8$ 


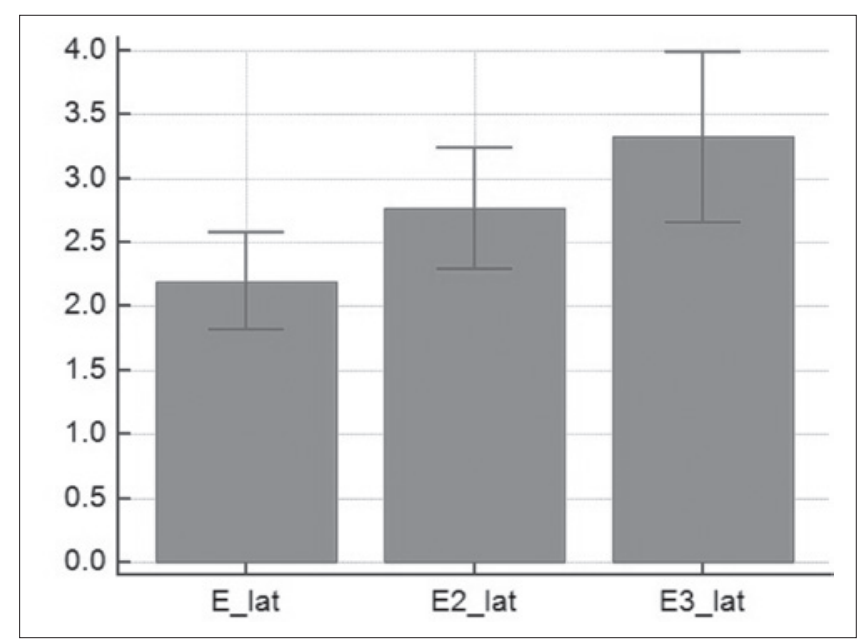

Fig. 2. The mean latency of SAN at different time intervals of the study (msec $\pm S D$ ). E_lat: pre-operative value; E2_lat: 1 month post-operative; E3_lat: 6 months postoperative.

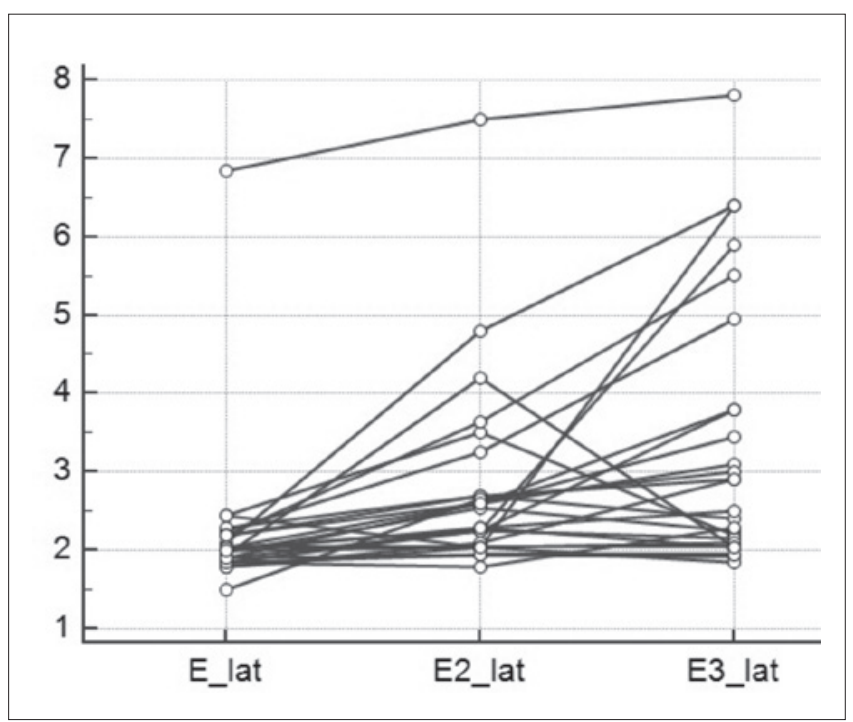

Fig. 3. Latency of $S A N$ (msec) of individual subjects $(n=40)$ at different time intervals.

E_at: pre-operative value; E2_lat: 1 month post-operative; E3_lat: 6 months postoperative.

$\mathrm{mV})$ compared to pre-operative value $(8.12 \pm 0.41 \mathrm{mV}$, $\mathrm{p}<0.01)$, this increased at 6 months $(6.15 \pm 1.43 \mathrm{mV})$. In comparison to the value at one month, this increase in amplitude was statistically significant $(\mathrm{p}<0.001)$ The values for latency and amplitude at different periods for postoperative neck irradiation and surgery alone group are summarised in Table II.

Arm abduction test and NDQL questionnaire: On goniometric analysis, the mean $( \pm \mathrm{SD})$ preoperative and postoperative scores were $4.9( \pm 0.04)$ and 3.23 $( \pm 0.53)$, respectively, indicating a decrease in arm abduction postoperatively (chi square test, $\mathrm{p}<0.001$ ). The

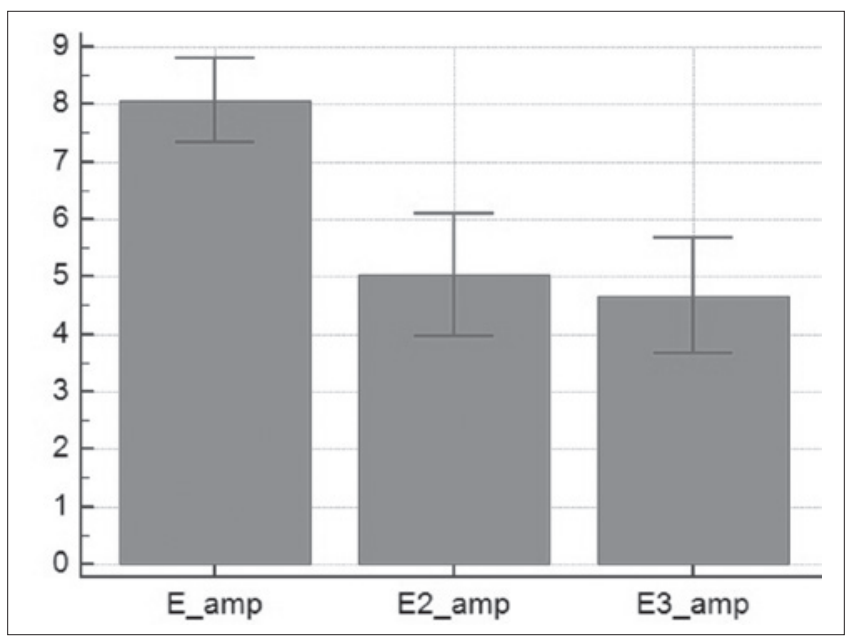

Fig. 4. The mean amplitude ( $\mathrm{mV} \pm \mathrm{SD})$ at different time intervals. E_amp: pre-operative value; $E_{-} 2$ amp: one month post-operative; $E_{-} 3$ amp: 6 months post-operative.

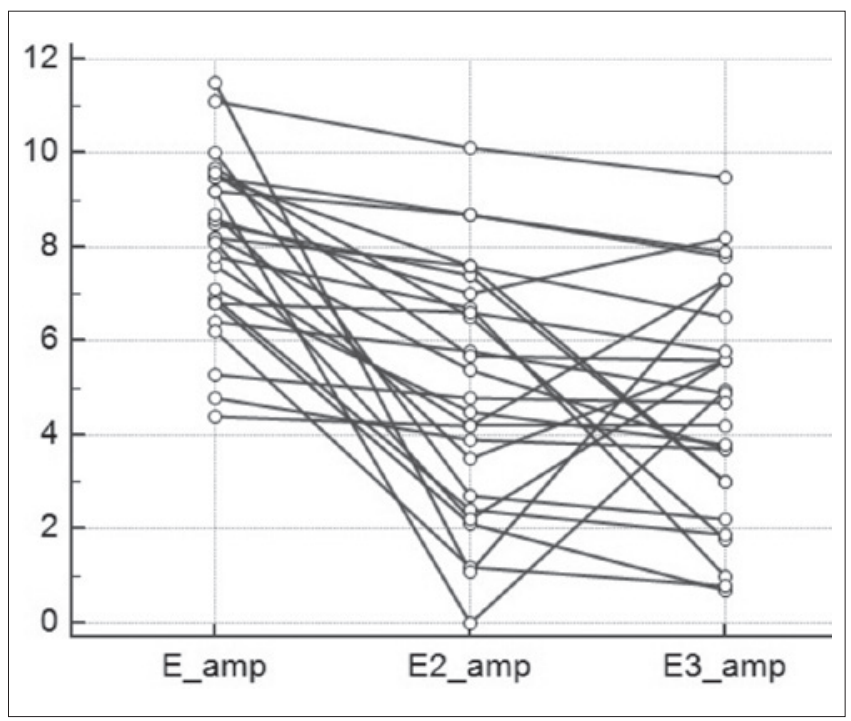

Fig. 5. The amplitude ( $\mathrm{mV}$ ) of study population $(n=40)$ at different time intervals.

E_amp: pre-operative value; $E_{2} 2$ amp: one month post-operative; $E \_3$ amp: 6 months post-operative.

mean pre-and post-operative scores for the questionnaire were $7.05 \pm 0.03$ and $11.05 \pm 0.33$, respectively, indicating there was a marginal decrease in the quality of life postoperatively that was statistically significant (chi square test, $\mathrm{p}<0.001$ ).

\section{Venous study}

The results of venous study (diameter and velocity) are summarised in the Table III. The results were compared by paired $t$ test and the differences were statistically significant. Two patients showed partial occlusion of the vein by thrombus at 1 month postoperatively. 
Table II. NCS in adjuvant neck radiation and surgery alone groups (mean + SD).

\begin{tabular}{lccc} 
NCS Parameters & $\begin{array}{c}\text { Adjuvant } \\
\text { irradiation } \\
(\mathbf{n}=35)\end{array}$ & $\begin{array}{c}\text { Surgery } \\
\text { alone } \\
(\mathbf{n}=5)\end{array}$ & $\begin{array}{c}\mathbf{P} \\
\text { value }\end{array}$ \\
Mean pre operative latency (msec) & $2.12 \pm 0.7$ & $2.11 \pm 0.32$ & 0.4 \\
Mean latency at one month (msec) & $2.78 \pm 1.07$ & $2.65 \pm 1.38$ & 0.8 \\
Mean latency at 6 months (msec) & $3.07 \pm 1.16$ & $2.66 \pm 1.34$ & 0.4 \\
Mean pre operative amplitude (mV) & $8.01 \pm 0.32$ & $8.12 \pm 0.41$ & 0.3 \\
Mean amplitude at one month (mV) & $5.60 \pm 1.03$ & $2.20 \pm 0.80$ & $<0.01$ \\
Mean amplitude at 6 months (mV) & $3.07 \pm 1.16$ & $6.15 \pm 1.43$ & 0.28 \\
\hline
\end{tabular}

Table III. Results of the venous Doppler study at different time intervals.

\begin{tabular}{lcc} 
Vein diameter $(\mathrm{mm})$ & Mean \pm SD & p value \\
Preoperative & $11.43 \pm 0.35$ & \\
Postoperative at 1 month & $9.65 \pm 0.46$ & $<0.001$ \\
Vein velocity $(\mathrm{cm} / \mathrm{sec})$ & & \\
Preoperative & $28.05 \pm 2.07$ & \\
Postoperative at 1 month & $31.05 \pm 2.32$ & 0.0544 \\
\hline
\end{tabular}

\section{Discussion}

The modified radical neck dissection in association with resection of the primary tumour has been the standard of care for clinically node positive operable OSCC owing to the complications resulting from sacrifice of SAN and IJV as well as the comparable outcomes as with the classical radical neck dissection. However, MND may also be associated with disability secondary to the surgical technique itself, or proximity of the lymphatics to neurovascular structures. The reported nerve dysfunction rates following MND ranges from $28 \%$ to $45 \%{ }^{81011}$. The possible reasons can be surgical technique of excessive handling with traction injury, microtrauma due to electrodiathermy, devascularisation and adjuvant treatments such as cisplatin based chemotherapy and radiotherapy ${ }^{12}$. Also, the forced immobilisation of the nerve resulting in shoulder stiffness may contribute to shoulder dysfunction postoperatively, which can be managed by aggressive physiotherapy. Some refinements in surgical techniques such as early identification of the nerve, preservation of the level IIb nodes, especially in $\mathrm{cNO}$ neck, minimising the manipulation of the SAN and IJV and avoidance of electrodiathermy near neurovascular structures may minimise disability.

In the present study, there was a statistically significant increase in mean latency of MAP and decrease in the mean amplitude of the MAP following surgery, suggesting nerve dysfunction. These results are in line with earlier studies ${ }^{813-15}$. Though the impact of adjuvant radiation was not assessed separately, even in 5 of the patients who did not receive any postoperative neck irradiation, the values at 6 months were less than preoperative values. Furthermore, the mean amplitude at one month in the adjuvant RT group $(5.6 \pm 1.03 \mathrm{mV})$ was more than the mean amplitude in the surgery alone group $(2.2 \pm 0.8 \mathrm{mV}$, Table II), which was statistically significant. One interesing finding with respect to mean latency and amplitude in the no radiation group was that the 6 month postoperative values improved from those at 1 month suggesting progressive nerve recovery following surgery. This calls into question whether adjuvant neck irradiation interferes with postoperative neurological recovery, which can only be answered by larger or preferably randomised studies. With respect to arm abduction, which indirectly assess SAN function, the mean score of 3.23 corresponded to an angle between $150^{\circ}$ to $180^{\circ}$ and there was a significant reduction in arm abduction both pre-and postoperatively. Though there was a statistically significant reduction in quality of life following treatment as assessed with the questionnaire, this did not translate into any meaningful clinical effect. The reason for this discrepancy can be explained by the high neurological reserve and the decreased action of the trapezius muscle being compensated by other arm abductors like supraspinatus, teres major and deltoid. Furthermore, all patients, as per protocol, received post-operative shoulder and neck physiotherapy which also could have contributed favourably to the quality of life scoring.

The patency of the IJV following preservation ranges from $74 \%$ to $100 \%$ and the prevalence of thrombus ranges from $5 \%$ to $26 \%^{16-18}$. The possible reasons could be surgical technique of neck dissection with ligation of small branches and the external compression by the myocutaneous flaps used for reconstruction ${ }^{819}$. In the present study, only $5 \%$ of the veins developed partial thrombus $(p>0.4)$. The studies by Xing et al. ${ }^{20}$ and Maria et al. ${ }^{12}$ showed similar results, whereas the study by De Bree et al. ${ }^{18}$ showed a significant change in patency caused by surgery. Following surgery, there was a significant decrease in the diameter of the vein as well as an increase in the velocity of blood flow, which could be due to luminal narrowing because of extrinsic compression by the myocutaneous flap used in these patients for oral reconstruction.

\section{Conclusions}

In conclusion, the present study highlights nerve and vein dysfunction following MND type II in patients undergoing surgery for OSCC. Although nerve dysfunction compromised shoulder abduction, vein dysfunction rarely resulted in any clinical impact. 


\section{References}

1 National Comprehensive Cancer Network. Head and Neck Cancers (Version 2.2016). Available from https://www.nccn. org/professionals/physician_gls/pdf/head-and-neck.pdf. Accessed October 26, 2016.

2 International Agency for Research on Cancer. GLOBOCAN 2012 estimated cancer incidence, mortality and prevalence worldwide in 2012. Available from http://globocan.iarc.fr/Pages/fact_sheets_population.aspx. Accessed October 26, 2016).

3 Shaw JP, Patel SG. Oral cavity and oropharynx In: Head and neck surgery and oncology. Third edition. China: Elsevier; 2007. p. 175-182.

4 Gavilan C, Gavilan J. Five-year results of functional neck dissection for cancer of the larynx. Arch Otolaryngol Head Neck Surg 1989;115:1193-6.

5 Ferlito A, Rinaldo A, Robbins KT, et al. Neck dissection: past, present and future? J Laryngol Otol 2006;120:87-92.

$6 \mathrm{Kim}$ DH, Cho YJ, Tiel RL, et al. Surgical outcomes of 111 spinal accessory nerve injuries. Neurosurgery 2003;53:1106-12.

7 Fisher CB, Mattox DE, Zinreich JS. Patency of the internal jugular vein after functional neck dissection. Laryngoscope 1988;98:923-7.

8 Giordano L, Sarandria D, Fabiano B, et al. Shoulder function after selective and super selective neck dissections: clinical and functional outcomes. Acta Otorhinolaryngol Ital 2012;32:376-9.

9 Surface ElectroMyoGraphy for the Non-Invasive Assessment of Muscles (SENIAM) Project Group recommendations. Available online https:// http://www.seniam.org/. Accessed October 26, 2016.

10 Restrepo CE, Tubbs RS, Spinner RJ. Expanding what is known of the anatomy of the spinal accessory nerve. Clin Anat 2015;28;467-71.
11 Ahlberg A, Nikolaidis P, Engstrom T, et al. Morbidity of supraomohyoid and modified radical neck dissection combined with radiotherapy for head and neck cancer, a prospective longitudinal study. Head Neck 2012;34:66-72.

12 Prim M, Deigo J, Fernandez A, et al. Patency and flow of internal jugular vein after neck dissection. Laryngoscope 2000;110:47-50.

13 Cappiello J, Piazza C, Giudice M, et al. Shoulder disability after different selective neck dissections (levels II-IV versus levels $(I-V)$ : a comparative study. Laryngoscope 2005;115:259-63.

14 Tsuji T, Tanuma A, Onitsuka T, et al. Electromyographic findings after different selective neck dissections. Laryngoscope 2007;117:319-22.

15 Lima LP, Ali A, Neutzling LC. Spinal accessory nerve neuropathy following neck dissection. Braz J Otorhinolaryngol 2011:77:259-62.

16 Ascher E, Salles-Cunha S, Hingorani A. Morbidity and mortality associated with internal jugular vein thromboses. Vasc Endovascular Surg 2005;39:335-9.

17 Brown DH, Mulholland S, Yoo JH, et al. Internal jugular vein thrombosis following modified neck dissection: implications for head and neck flap reconstruction. Head Neck 1998;20:169-74.

18 De Bree R, Vandenberg FG, Van Shaick C, et al. Assessment of patency of the internal jugular vein following neck dissection and microvascular flap reconstruction by power Doppler ultrasound. J Laryngol Otol 2002;116:622-6.

19 Inoue H, Nibu K, Saito M, et al. Quality of life after neck dissection. Arch Otolaryngol Head Neck Surg 2006;132:662-6.

20 Xing W, Cai X, Gu J. [Patency and flow of the internal jugular vein after selective neck dissection]. Lin Chung Er Bi Yan Hou Tou Jing Wai Ke Za Zhi 2012;26:385-8. 